\title{
Fibroareolar Tissue Wrap-Around Flap for Tip Plasty in Rhinoplasty in Asians
}

\author{
Hyung Min Lee ${ }^{1}$, \\ Cheol Keun Kim ${ }^{1}$, \\ Soon Heum Kim ${ }^{1}$, \\ Myung Chul Lee ${ }^{2}$, Jee Nam Kim², \\ Dong Hyeok Shin², \\ Hyun Gon Choi ${ }^{2}$, Dong In $\mathrm{Jo}^{1}$ \\ ${ }^{1}$ Department of Plastic and \\ Reconstructive Surgery, Konkuk \\ University Chungju Hospital, Konkuk \\ University School of Medicine, Chungju; \\ ${ }^{2}$ Department of Plastic and \\ Reconstructive Surgery, Konkuk \\ University Medical Center, Konkuk \\ University School of Medicine, Seoul, \\ Korea
}

The authors did not receive any funding or benefits from any companies related directly or indirectly to the subject of this paper.

No potential conflict of interest relevant to this article was reported.
Background Asians tend to have bulbous, wide, and thick-skinned noses, leading to limitations in tip augmentation. Therefore, following various tip plasty procedures, the use of a dermal graft or a fat graft may be considered for additional augmentation. For definition of the Asian nasal tip, thick fibroareolar and subcutaneous tissues are resected. However, these previously discarded tissues may be a useful material for tip augmentation. Hence, we would like to propose the fibroareolar tissue wrap-around flap as an adjuvant augmentation procedure.

Methods Tip plasty procedures, including various suture techniques and cartilage grafts, were performed. Near the scroll area, the fibroareolar tissues above both lower lateral cartilages were dissected in the supraperichondrial plane. Caudally based fibroareolar tissue flaps were elevated around the nasal tip. The tip portion of the alar cartilage framework was covered with the flaps. The flaps were fixed to the middle or medial crura of the lower lateral cartilages.

Results A total of 13 patients underwent the fibroareolar tissue wrap-around flap procedure for nasal tip plasty. No complaints were reported at follow-up by 12 patients. No cases of major infection, hematoma, or vascular compromise occurred.

Conclusions The fibroareolar tissue wrap-around flap offers several advantages for tip plasty in Asians, including additional tip projection, soft tissue volume reduction, redraping, and a naturally soft nasal tip, and likely aids in preserving the volume of other cartilage grafts. Therefore, this fibroareolar tissue wrap-around flap is worth considering as a useful adjuvant option for tip plasty in rhinoplasty in Asian patients.

Keywords Asian continental ancestry group, Rhinoplasty, Surgical flaps

\section{INTRODUCTION}

One of the most challenging problems in rhinoplasty is a thick, heavy, and poorly refined nasal tip. Tip surgery remains the most discussed aspect of rhinoplasty, as it involves complex 3-dimensional (3D) anatomical structures. Surgical procedures for the tip

Received: Jul 30, 2016 Revised: Sep 26, 2016 Accepted: Oct 4, 2016 Correspondence: Dong In Jo Department of Plastic and Reconstructive Surgery, Konkuk University Chungju Hospital, Konkuk University School of Medicine, 82, Gugwon-daero, Chungju 27376, Korea.

E-mail: cozarmd@kku.ac.kr

Copyright @ 2016 The Korean Society for Aesthetic Plastic Surgery.

This is an Open Access article distributed under the terms of the Creative Commons Attribution Non-Commercial License (http://creativecommons.org/licenses/by-nc/4.0/) which permits unrestricted non-commercial use, distribution, and reproduction in any medium, provided the original work is properly cited. www.e-aaps.org include suture techniques; cartilage remodeling techniques such as crushing, scoring, or dividing; and the use of cartilaginous grafts $[1,2]$.

To obtain a harmonious and balanced appearance of the nose, sculpting the nasal tip should be the main goal of rhinoplasty. For obtaining the desired definition, a sufficient cartilage framework and proper coverage with soft tissue are needed. Asians tend to have a bulbous and wide nose with thick skin [3]. Additionally, limitations may exist in obtaining the desired tip definition and augmentation, such as an insufficient cartilage framework or an improper soft tissue envelope. Therefore, following various tip plasty procedures, the use of a dermal graft or a fat graft may be considered for additional augmentation. In some studies, for the definition of the nasal tip in Asians, thick fibroareolar and subcutaneous tissues have been resected $[4,5]$. However, we suggest that this previously discarded tissue may be a useful material for tip augmentation. 
In our clinic, autologous cartilage for rhinoplasty is mainly harvested from the nasal septum to minimize donor site morbidity. If it is not possible to use the nasal septum, auricular conchal cartilage is harvested. For additional augmentation, an allograft, a dermal graft, or a fat graft is used. However, in cases of augmentation confined to the nasal tip, the fibroareolar tissue wrap-around flap also appears to be useful. In this study, we would like to propose the fibroareolar tissue wrap-around flap as an adjuvant augmentation procedure.

\section{METHODS}

\section{Patients}

From June 2014 to May 2016, a total of 13 patients underwent the fibroareolar tissue wrap-around flap procedure for nasal tip plasty. Of these patients, 7 underwent primary rhinoplasty and 6 underwent secondary rhinoplasty. The mean size of the right flap was $1.21 \times 0.47 \mathrm{~cm}$, and the mean size of the left flap was $1.11 \times 0.45$ $\mathrm{cm}$. Patients' photographs and charts were reviewed. The mean follow-up period was 9.8 months (Table 1).

\section{Surgical procedure}

Under general or local anesthesia, $0.2 \%$ lidocaine with 1:100,000 epinephrine was injected. Open rhinoplasty was performed using a transcolumellar incision. The medial and middle crural cartilage was dissected in the supraperichondrial plane and shifted anteriorly. Further deep dissection was avoided in order to prevent injury of the soft tissues behind the medial and middle crura. On the caudal border of the lateral crus of lower lateral cartilage, a vestibular incision was made and connected to the columellar incision. Dissection was performed cephalad and laterally just above the fibroareolar layer along the dome of the lateral crus of lower lateral cartilage. Before the nasal hinge area, the dissection plane was changed to the supraperichondrial plane in order to avoid interrupting the blood supply to the skin envelope. Dissection was performed until the skin soft tissue envelope had expanded sufficiently. Retraction of the envelope exposed the nasal osseocartilaginous framework. The lower lateral cartilage was separated from the inferior edge of the upper lateral cartilage. The membranous septum and nasal hinge complex were released to provide mobility of the lower lateral cartilage.

Tip plasty procedures, such as columellar strut grafts and septal extension grafts, were performed using autologous cartilage according to patients' individual conditions. Near the scroll area, the fibroareolar tissues above both lateral crura of the alar cartilages were dissected in the supraperichondrial plane towards the nasal tip. Caudally based fibroareolar tissue flaps were elevated and prepared around the nasal tip. Cartilage framework modifications, such as interdomal sutures, transdomal sutures, or suture extension of the medial crura, were performed. The newly created tip portion of
Table 1. Patient demographics

\begin{tabular}{|c|c|c|c|c|c|c|}
\hline No. & $\begin{array}{l}\text { Sex/ } \\
\text { Age }\end{array}$ & Operation & $\begin{array}{l}\text { Anes- } \\
\text { thesia }\end{array}$ & $\begin{array}{l}\text { Cartilage } \\
\text { source }\end{array}$ & $\begin{array}{l}\text { Flap size } \\
\text { [cm] }\end{array}$ & $\begin{array}{l}\text { Follow-up } \\
\text { period } \\
\text { (month) }\end{array}$ \\
\hline 1 & $M / 38$ & Primary & Local & Septal & $\begin{array}{l}\text { R) } 1.2 \times 0.5 \\
\text { L) } 1.1 \times 0.5\end{array}$ & 12 \\
\hline 2 & $F / 36$ & Secondary & Local & Auricular & $\begin{array}{l}\text { R) } 1.0 \times 0.4 \\
\text { L) } 1.0 \times 0.4\end{array}$ & 11 \\
\hline 3 & $M / 26$ & Primary & General & Septal & $\begin{array}{l}\text { R) } 1.3 \times 0.5 \\
\text { L) } 1.1 \times 0.4\end{array}$ & 12 \\
\hline 4 & $F / 27$ & Primary & Local & Septal & $\begin{array}{l}\text { R) } 1.1 \times 0.4 \\
\text { L) } 0.9 \times 0.4\end{array}$ & 9 \\
\hline 5 & $F / 38$ & Primary & General & Septal & $\begin{array}{l}\text { R) } 1.4 \times 0.6 \\
\text { L) } 1.2 \times 0.5\end{array}$ & 8 \\
\hline 6 & $M / 30$ & Secondary & Local & Auricular & $\begin{array}{l}\text { R) } 1.5 \times 0.6 \\
\text { L) } 1.2 \times 0.5\end{array}$ & 6 \\
\hline 7 & $F / 24$ & Secondary & General & Septal & $\begin{array}{l}\text { R) } 0.9 \times 0.3 \\
\text { L) } 1.1 \times 0.4\end{array}$ & 12 \\
\hline 8 & $F / 32$ & Primary & Local & $\begin{array}{l}\text { None (only } \\
\text { modification) }\end{array}$ & $\begin{array}{l}\text { R) } 1.2 \times 0.4 \\
\text { L) } 1.1 \times 0.5\end{array}$ & 18 \\
\hline 9 & $F / 33$ & Primary & Local & Auricular & $\begin{array}{l}\text { R) } 1.1 \times 0.5 \\
\text { L) } 1.1 \times 0.4\end{array}$ & 6 \\
\hline 10 & $\mathrm{~F} / 30$ & Secondary & Local & Septal & $\begin{array}{l}\text { R) } 1.3 \times 0.5 \\
\text { L) } 1.2 \times 0.5\end{array}$ & 10 \\
\hline 11 & $F / 26$ & Primary & Local & Septal & $\begin{array}{l}\text { R) } 1.5 \times 0.5 \\
\text { L) } 1.4 \times 0.4\end{array}$ & 12 \\
\hline 12 & $F / 36$ & Secondary & Local & $\begin{array}{l}\text { None (modifi- } \\
\text { cation and Al- } \\
\text { loDerm) }\end{array}$ & $\begin{array}{l}\text { R) } 1.0 \times 0.4 \\
\text { L) } 0.9 \times 0.4\end{array}$ & 9 \\
\hline 13 & $M / 19$ & Secondary & General & Auricular & $\begin{array}{l}\text { R) } 1.2 \times 0.5 \\
\text { L) } 1.1 \times 0.5\end{array}$ & 3 \\
\hline
\end{tabular}

$M$, male; $F$, female; $R$, right; $L$, left.

the alar cartilage framework was hung and fixed over the septum at the most anterior and caudal points. Additional shield grafts were performed, if necessary. The prepared fibroareolar tissue flaps were trimmed into the necessary shape. The finally created tip portion of the alar cartilage framework was covered with the flaps. The flaps were fixed to the middle or medial crura of the lower lateral cartilages (Fig. 1). These soft and tender flaps were well adapted under the skin envelope, without any dead space. Meticulous bleeding control was achieved using electrocautery. It was important to prevent fibrous scar contracture by preventing hematoma. The nose was again covered with the nasal skin soft tissue envelope without any tension. Incisions were closed with 5-0 vicryl and 6-0 nylon sutures. Vaseline gauze packing into the nostril and external compressive dressing were applied, and then removed on postoperative days 1-2 and 7, respectively.

\section{RESULTS}

The follow-up results involved no complaints in 12 of the 13 pa- 

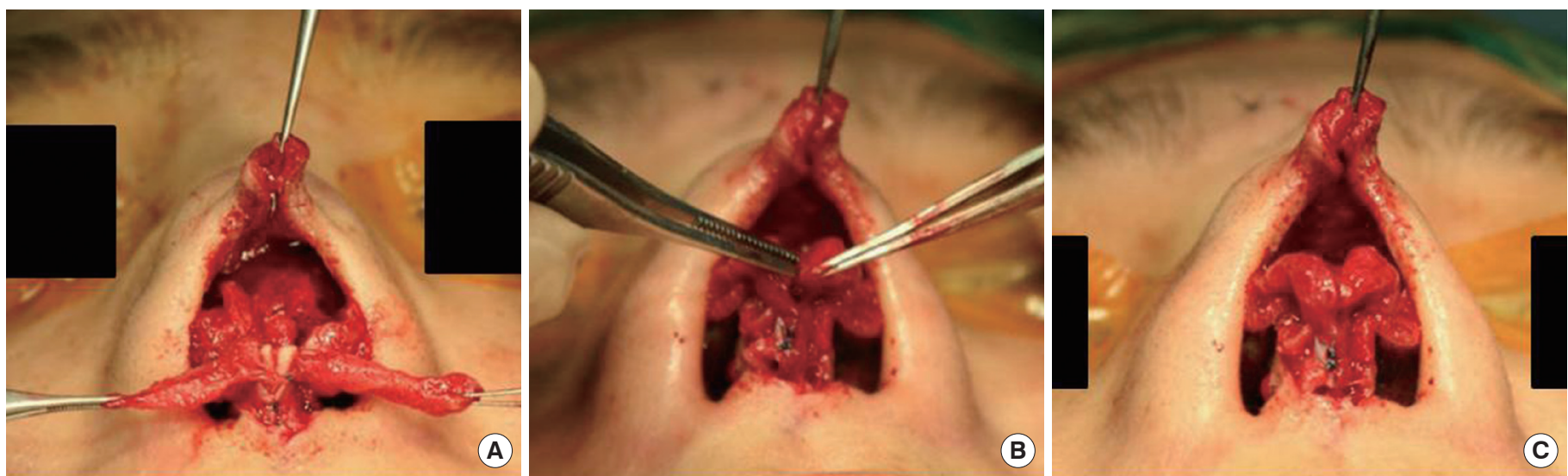

Fig. 1. Intraoperative photographs. This patient underwent primary rhinoplasty using a silicone implant 2 years previously. (A) Supraperichondrial plane dissection above the lower lateral cartilages. (B) The nasal tip covered by the elevated flaps. (C) Image taken before the lower lateral cartilage modification and fixation of the flaps to the middle or medial crura of the lower lateral cartilage.
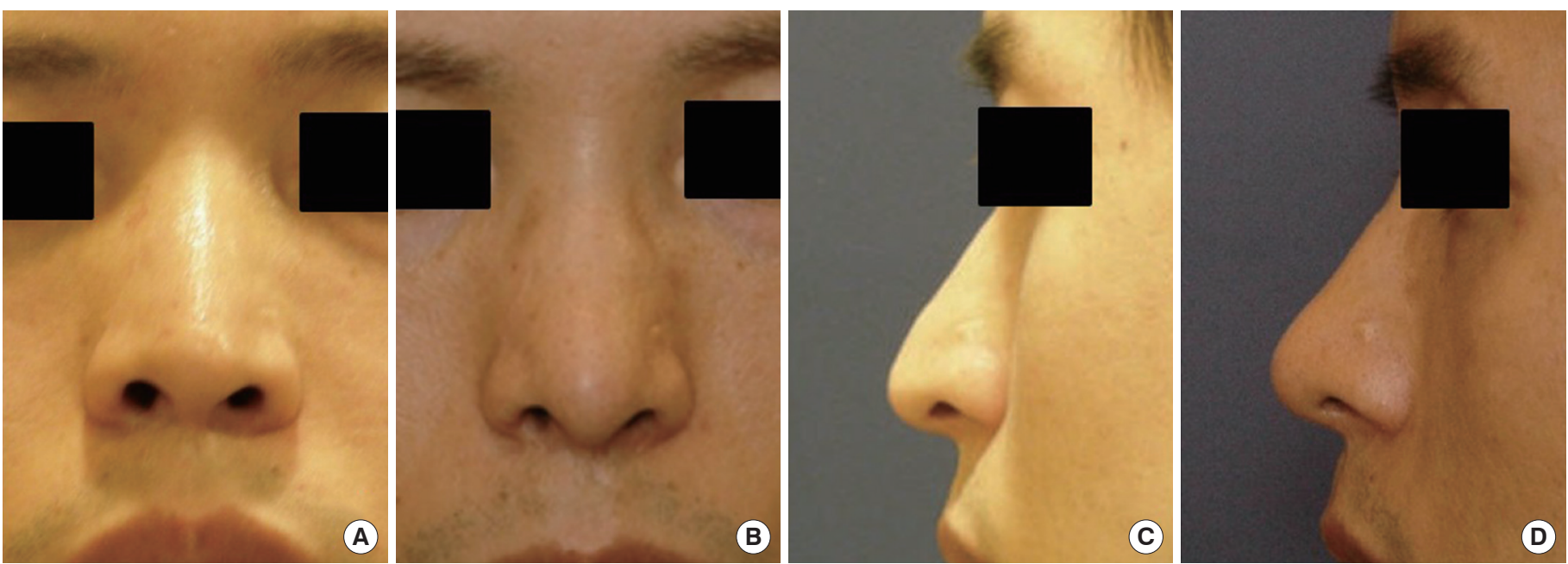

Fig. 2. Case 1. (A, C) A 38-year-old man presented with complaints of a droopy and under-projected nasal tip and a retracted ala. (B, D) At 12 months after the procedure, the patient exhibited increased tip projection, improved nasal ptosis, and improved alar retraction.

tients (92.3\%). No visible or palpable irregularities occurred on the nasal tip. No cases of major postoperative infection, hematoma, or vascular compromise of the nasal skin were noted. An undercorrected infranasal tip projection was reported by 1 patient within 60 days postoperatively. The patient underwent cell-assisted lipotransfer and had a successful outcome.

\section{Case 1}

A 38-year-old man presented with complaints of a droopy, underprojected nasal tip and a retracted ala. He had no history of previous operations. The operative plan was as follows: open rhinoplasty via the transcolumellar and vestibular incisions with suture extension of the medial crura, tip refinement with an interdomal suture, shield graft using a septal cartilage, an extension graft between the upper and lower lateral cartilage for alar retraction correction, and a fibroareolar tissue wrap-around flap. At 12 months after the procedure, the patient exhibited increased tip projection, improved nasal ptosis, and improved alar retraction (Fig. 2).

\section{Case 2}

A 27-year-old woman presented with complaints of an under-projected and bulbous nasal tip and bowing of the nasal dorsum. She had no history of previous operations. The operative plan was as follows: open rhinoplasty via transcolumellar and vestibular incisions with suture extension of the medial crura, a shield graft using septal cartilage, tip refinement with interdomal suturing, and a fibroareolar tissue wrap-around flap. At 9 months after the procedure, the patient had a straight dorsum, increased tip projection, and a symmetrical and narrow nasal tip (Fig. 3). 

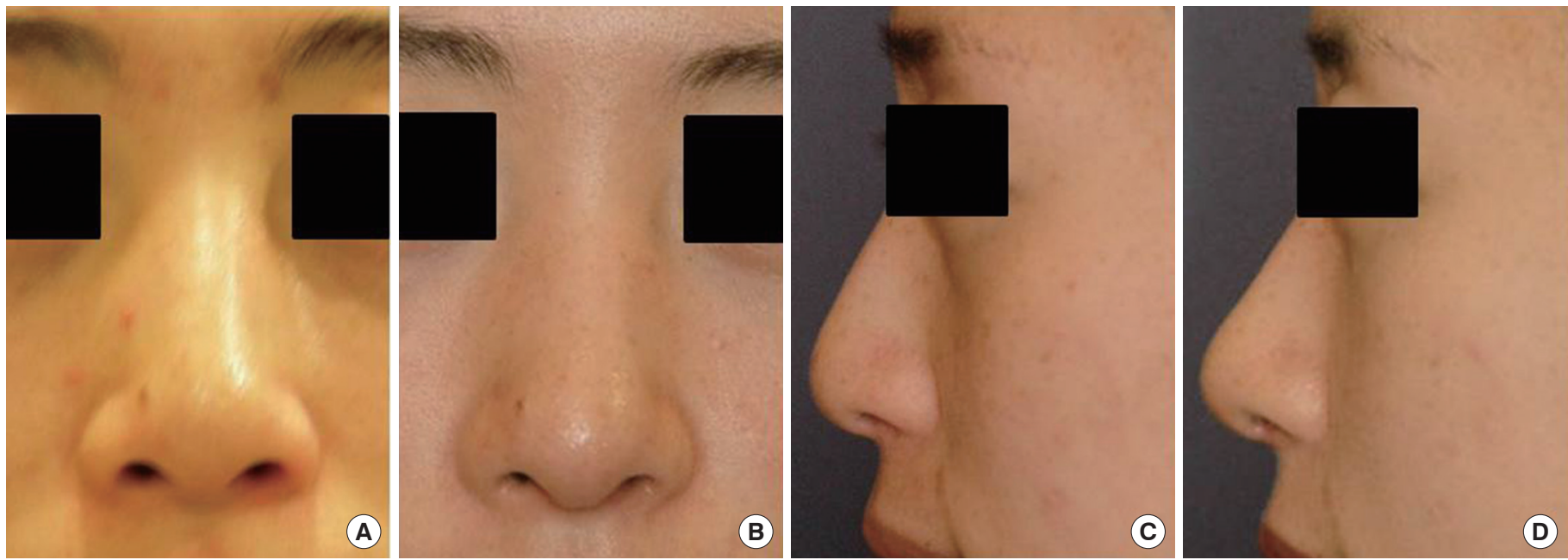

Fig. 3. Case 2. $(A, C)$ A 27-year-old woman presented with complaints of an under-projected and bulbous nasal tip and bowing of the nasal dorsum. (B, D) At 9 months after the procedure, the patient had a straight dorsum and increased tip projection.

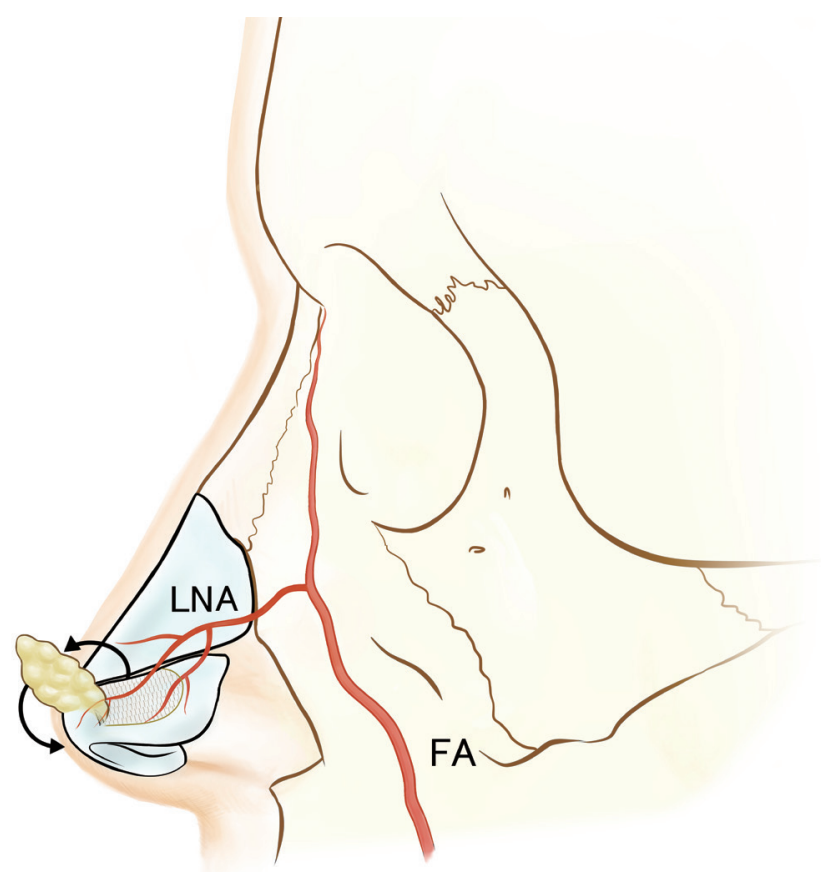

Fig. 4. Schematic illustration of the fibroareolar tissue wrap-around flap. The distally based fibroareolar tissue flap is elevated above the perichondrium and anchored at the medial or middle crura of the lower lateral cartilage. The flap is supplied by the lateral nasal artery. FA, facial artery; LNA, lateral nasal artery.

\section{DISCUSSION}

A poorly refined and bulbous nasal tip is one of the most common problems encountered in Asian patients who desire rhinoplasty. However, achieving an aesthetically pleasing nasal tip is not easy because the nasal tip has a complex $3 \mathrm{D}$ anatomical structure and
Asians have a thick skin-soft tissue envelope [6]. Various autologous cartilage grafts have been used for nasal tip projection, but many patients have insufficient autologous cartilage. Additionally, in Asian patients with a thick skin-soft tissue envelope, the effectiveness of only using suture techniques, such as interdomal or transdomal sutures, is doubtful [7]. In some studies, for definition of the nasal tip in Asians, thick fibroareolar and subcutaneous tissues were resected $[4,5]$. In such situations, the fibroareolar tissue wrap-around flap can be considered.

The fibroareolar tissue wrap-around flap uses soft tissue above the lower lateral cartilages. Especially in cases of open rhinoplasty via a transcolumellar incision, the columellar branch of the superior labial artery is cut; hence, the nasal soft tissue relies on the lateral nasal artery and the subdermal plexus [8]. For preparation of the flap, it is necessary to dissect just above the fibroareolar layer along the dome of the lateral cartilage on the tip and the alar area, meaning that special attention should be paid to avoid interrupting the blood supply to the skin envelope by changing the dissection plane to the supraperichondrial plane just before the dissection arrives at the nasal hinge area (Fig. 4).

The fibroareolar tissue wrap-around flap offers several advantages as an adjuvant augmentation procedure. First, this flap is effective if the harvested autologous cartilage is insufficient for tip plasty for any reason. The fibroareolar tissue flaps wrap around the newly created tip portion of the alar cartilage framework. By adding the wrapping tissue to the nasal tip, the tip projection can be increased. Additionally, the flap can help compensate for the asymmetrical thickness of the soft tissue of the nasal tip by adjusting the shape of the flap. Hence, it is helpful in achieving symmetrical tip projection.

Moreover, in patients with a bulbous and wide nasal tip, especially in Asians, the elevation of this flap itself reduces the soft tis- 
sue above the lower lateral cartilage. Hence, it helps to create a narrower nasal tip. Moreover, the thickness of the skin-soft tissue envelope affects the results of tip plasty procedures. Hence, the reduced volume of the skin-soft tissue envelope can facilitate more effective reduction of the width of the nose using the interdomal and transdomal suture techniques [7].

In addition, the wrapped flap acts as a cushion for the natural nose. Many rhinoplasty surgeons bevel the edges of the cartilage graft to prevent the graft from being palpable [2]. However, in patients with very thin skin, palpability or visibility of the cartilage cannot be avoided. This may be an important factor contributing to patients' dissatisfaction. Especially in secondary rhinoplasty cases, patients who underwent primary rhinoplasty using a silicone implant had thin skin on the nasal tip. The soft tissue that is wrapped around the anterior portion of the tip like a cushion can help obtain a natural and aesthetic nasal tip.

Finally, other cartilage grafts that are used for tip plasty can be expected to maintain their volume, as they are covered with the fascia-like fibroareolar tissue. Usually, diced cartilage grafts can be covered by the temporalis fascia or the rectus muscle fascia to reduce resorption of the cartilages $[9,10]$. As it has the same purpose as the fascia graft, the fibrous characteristics of this flap can be expected to help reduce resorption of other cartilage grafts on the tip area.

Free dermal and free fat grafts have been widely used for correcting contour deformities, and they have shown good postoperative results [11]. However, resorption, the need for repeated augmentation, and donor site morbidity are important limitations [12]. With regard to cases of augmentation confined only to the nasal tip area, which is a relatively small sized area, we suggest that the fibroareolar tissue wrap-around flap has no donor site morbidity because the flap uses soft tissue very close to the nasal tip. In secondary cases, the fibroareolar tissue may be dense and not flexible. However, in this study, we did not encounter any case in which the scar tissue was too dense to be handled.

The fibroareolar tissue wrap-around flap offers several advantages for tip plasty in Asians, including additional tip projection, soft tissue volume reduction, redraping, and a naturally soft nasal tip, and likely aids in preserving the volume of other cartilage grafts. Additionally, we suggest that this flap is more beneficial than a free dermal graft or a free fat graft in cases of augmentation confined to the nasal tip. Therefore, this fibroareolar tissue wrap-around flap is worth considering as a useful adjuvant option for tip plasty in rhinoplasty in Asian patients.

\section{PATIENT CONSENT}

Patients provided written consent for the use of their images.

\section{REFERENCES}

1. Gruber RP, Chang E, Buchanan E. Suture techniques in rhinoplasty. Clin Plast Surg 2010;37:231-43.

2. Gunter JP, Landecker A, Cochran CS. Frequently used grafts in rhinoplasty: nomenclature and analysis. Plast Reconstr Surg 2006;118:14e29 e.

3. Ishii CH. Current update in asian rhinoplasty. Plast Reconstr Surg Glob Open 2014;2:e133.

4. Gao F, Yin NB, Ji Y, et al. Alar cartilage used as tip grafts in secondary silicone augmentation rhinoplasty in Chinese patients. J Craniofac Surg 2011;22:614-6.

5. Lee KC, Kwon YS, Park JM, et al. Nasal tip plasty using various techniques in rhinoplasty. Aesthetic Plast Surg 2004;28:445-55.

6. Kim DA, Jeong JY, Oh SH. Bulbous tip correction focusing on skin soft tissue envelope in Asian rhinoplasty. Arch Aesthetic Plast Surg 2014;20:140-7.

7. Tasman AJ, Helbig M. Sonography of nasal tip anatomy and surgical tip refinement. Plast Reconstr Surg 2000;105:2573-9.

8. Gruber RP, Stepnick D. Rhinoplasty: Current concepts, an issue of Clinics in Plastic Surgery. Philadelphia, PA: Saunders; 2010.

9. Calvert J, Brenner K. Autogenous dorsal reconstruction: maximizing the utility of diced cartilage and fascia. Semin Plast Surg 2008;22:110-9.

10. Cerkes N, Basaran K. Diced cartilage grafts wrapped in rectus abdominis fascia for nasal dorsum augmentation. Plast Reconstr Surg 2016; 137:43-51.

11. Reich J. The application of dermis grafts in deformities of the nose. Plast Reconstr Surg 1983;71:772-82.

12. Erdogan B, Tuncel A, Adanali G, et al. Augmentation rhinoplasty with dermal graft and review of the literature. Plast Reconstr Surg 2003;111: 2060-8. 